\title{
Políticas e práticas de saúde e equidade*
}

\author{
HEALTH POLICY AND PRACTICE TOWARDS EQUITY
}

POLÍTICAS, PRÁCTICAS DE SALUD Y EQUIDAD

\section{Renilson Rehem de Souza'}

\section{RESUMO}

$\mathrm{O}$ artigo discute os conceitos de igualdade e eqüidade em saúde no contexto do Sistema Único de Saúde (SUS). Para tanto o autor comenta sobre os princípios do SUS com destaque para a Universalidade e a Integralidade. Faz uma breve revisão dos antecedentes do SUS, bem como de seu processo de implantação. Comenta o contexto de grandes avanços tecnológicos e suas implicações na qualidade da atenção à saúde e em seus custos. Apresenta alguns avanços alcançados pelo SUS no Brasil, e de modo particular, no Estado de São Paulo. Conclui com uma breve análise dos desafios do SUS, de modo especial, o acesso aos serviços em um contexto de necessidades crescentes e recursos limitados.

\section{DESCRITORES}

Sistema Único de Saúde. Políticas Públicas de Saúde. Eqüidade em saúde.

\section{ABSTRACT}

The article discusses the concepts of equality and equity in the health area in Brazilian scenario, which means under the Unified Health System (UHS). The author shows the principles of UHS, emphasizing the principles of Universality and Integrality. Also reviews briefly the history of UHS and its construction process. It shows singularity of present issues such as technological advances and its consequences to the quality of health attention, both reflecting to the costs of the health care. It analyses some advances that were possible in Brazilian health attention and especially in São Paulo State. In conclusion, he explains a brief analyze about UHS news challenges: the increasing of accessibility to the health services, increasing of needs and the limited resources.

\section{KEY WORDS}

Single Health System. Health Public Health. Equity in health.

\section{RESUMEN}

Este artículo discutió los conceptos de igualdad y equidad en salud, tomando como escenario el Sistema Único de Salud (SUS) de Brasil. Para tal, se realizó un comentario acerca de los principios del SUS, enfatizando la Universalidad y la Integralidad. Se hizo una breve revisión sobre la historia de la constitución del SUS y del proceso de implantación. Se comentó el contexto de los grandes avances tecnológicos y sus implicaciones en la calidad de la atención a la salud y en sus costos. Se presentaron algunos avances alcanzados por el SUS en Brasil, destacando el Estado de São Paulo. Se concluyó con un breve análisis de los desafíos del SUS, destacando el acceso a los servicios, en un contexto de crecientes necesidades y limitados recursos.

\section{DESCRIPTORES}

Sistema Único de Salud.

Políticas Públicas de Salud.

Equidad en salud.

\footnotetext{
Extraído do texto apresentado como abertura da Mesa Redonda Políticas e Práticas de Saúde Rumo à Eqüidade, no I Simpósio Internacional de Políticas e Práticas em Saúde na Perspectiva da Enfermagem, São Paulo, 3-4 set. 2007. 1 Médico. Mestre em

Administração de Saúde. Secretário Adjunto de Saúde do Estado de São Paulo. São Paulo, SP, Brasil. renilson.rehem@ gmail.com
} 


\section{INTRODUÇÃO}

Embora o tema proposto trate de políticas e práticas de saúde e equidade eu pensei que seria interessante, primeiro, compreendermos o conceito de equidade com referência ao conceito de igualdade e depois, então, discutiremos as políticas rumo à equidade porque o meu campo de trabalho tem mais a ver com políticas do que diretamente com estas práticas.

Na verdade, discutir a eqüidade é um avanço em relação à discussão da igualdade, porque é preciso que haja um mínimo de condição de igualdade para que se possa começar a discutir a eqüidade. $\mathrm{O}$ dicionário Houaiss diz que $a$ igualdade é o princípio segundo o qual todos os homens são submetidos à lei e gozam dos mesmos direitos e obrigações; a equidade seria o respeito à igualdade de direito de cada um, que independe da lei positiva, mas de um sentimento do que se considera justo, tendo em vista as causas $e$ as intenções ${ }^{(1)}$. Com isso, destaco o entendimento de que a equiidade, mais do que tratar todos iguais, teria um valor de justiça, ou seja, de se buscar dar mais a quem precisa mais. Neste sentido, é preciso ter clara a noção de direito de igualdade antes de discutir eqüidade, porque também equiidade não significa retirar direitos, mas respeitar o direito de que todos são iguais e buscar dar mais prioridade àquele que mais precisa. Com esta compreensão, a eqüidade em saúde implica em prover a cada um a atenção, as ações de saúde segundo suas necessidades. É claro que isso é um enorme desafio.

Na verdade, na história do nosso país, sempre tivemos grandes problemas de desigualdade. Antes de falar de eqüidade então, vamos tratar um pouco dos grandes problemas de desigualdade ${ }^{(2)}$. Sabe-se que sempre houve grandes desigualdades em relação às diversas regiões do país, a grupos sociais, a aspectos raciais, de gênero e ainda com relação a uma série de outras coisas. Nas ações dos serviços de saúde, tem-se buscado a redução dessas desigualdades com o SUS ${ }^{(3-4)}$, que traz avanços no sentido da igualdade e da eqüidade e da igualdade com universalidade. Então, uma das idéias básicas do SUS, do nosso sistema público, é que ele é universal, ou seja, todos têm o mesmo direito. Isso é uma coisa que pode parecer óbvia, que não mereceria nenhuma ênfase ou maior detalhamento, mas na verdade nem sempre foi assim. Antes do SUS, algumas pessoas tinham direito à previdência social e ao INAMPS e outras não tinham nenhum direito. As pessoas sem direitos eram atendidas pelo sistema, como caridade. As organizações filantrópicas ou sem finalidades lucrativas exerciam um papel de grande importância na atenção a essas pessoas que eram classificadas ou denominadas como indigentes. Essa foi uma mudança muito grande com a implantação do SUS, pois com o direito constitucionalmente assegurado, todos têm direito ao Sistema de Saúde, no sentido não só da universalidade, mas da integralidade que é tudo para todos. Ou seja, não se trata de alguma coisa para todos; não é só garantir a vacina ou outros aspectos da vigilância epidemiológica ou a consulta do pré-natal, mas é garantir tudo, inclusive aquelas ações mais complexas, de mais alto custo para todos, e assim garantir a universalidade e a integralidade. É claro que nesse balanço, de oferta e acesso, ainda existem muitas dificuldades, mas é necessário lembrar que o tempo de historia do SUS é muito pequeno.

Alguns dizem que o SUS começou em $1988^{(5)}$. Na verdade, ali foi a concepção mas a gestação foi bastante longa, não durou apenas nove meses. Porque a primeira lei, a 8.080 (3,6), a Lei Orgânica da Saúde foi promulgada em 1990. A segunda, que é tão orgânica quanto a primeira, que é a lei 8.142(4-6), também é de 1990. Mas, na minha avaliação, o inicio efetivo da implantação do SUS se deu a partir da Norma Operacional Básica de 1996, a NOB - 96 ${ }^{(7)}$ que começou a ser implantada em 1997 e 1998. Isto, porque só nesse momento todos os entes federados que integram o sistema, realmente passaram a fazer parte do mesmo e foi quando começou a mudar o modelo de financiamento. Ou seja, passou de um financiamento que era a exata continuidade do finan-ciamento da época do INAMPS para um novo modelo. $\mathrm{O}$ INAMPS não era um sistema universal, era um sistema contributivo e, portanto, gastava muito mais com cidades como São Paulo do que com Manaus, no Amazonas. Por outro lado, a participação dos municípios, quando havia, se dava por meio da remuneração contra prestação de serviços.

Então a partir da NOB 96 ${ }^{(7)}$, quando se implantou o financiamento per capita e o envolvimento de todos os municípios foi que efetivamente começou a implantação do SUS. Desse modo, o SUS tem muito pouco tempo de experiência para que se consiga vencer o desafio de tamanha desigualdade, pelo menos do ponto de vista da oferta e do acesso. $E$ também para melhorar a qualidade das práticas, que é um desafio enorme a ser enfrentado progressivamente, de forma que haja a necessária adequação destas práticas aos problemas de saúde da população. Pode parecer incrível, mas existem práticas de saúde que não são oportunas nem adequadas às necessidades de determinada população. A saúde tem essa característica. Há ainda mais um complicador que é que em determinado momento a prestação de serviço tenta e muitas vezes consegue gerar demanda mesmo sem haver necessidade.

A desigualdade em saúde, que pode ser visualizada por meio de diversos indicadores, na verdade, pode ser atribuída a fatores como desenvolvimento econômico, renda, educação, emprego, etc. Todas essas variáveis são distribuídas de forma desigual em nosso país. Assim, temos no Brasil, 
regiões, Estados, cidades, parcelas da população que habitam as cidades com condições absolutamente desiguais do ponto de vista da renda, da moradia, do acesso à educação, à saúde e a várias outras condições.

Em relação à atenção e às práticas, quando essas fazem parte de uma política de saúde voltada para a justiça social, representam um importante avanço, para a redução destas desigualdades $^{(8)}$. É isso que o SUS enquanto política pública procura fazer.

\section{POLÍTICAS E PRÁTICAS DE SAÚDE E EQÜIDADE}

Como disse anteriormente, o que existia antes do SUS era uma situação absolutamente instituída, oficial, pública e conhecida de todos que era, grosso modo, a existência de dois tipos, ou duas classes de cidadão. Aqueles que tinham a previdência e aqueles que não tinham cobertura, classificados como indigentes ${ }^{(9)}$. A situação era muito menos dramática do que seria hoje porque o avanço que o conhecimento na área da saúde, na área do diagnóstico e da assistência experimentou nestes últimos 20 a 30 anos modificou muito esse quadro. Naquela época, estava começando uma nova fase do desenvolvimento tecnológico e ainda não existiam terapia intensiva, transplante de órgãos, tomografia computadorizada, ressonância magnética. Os recursos eram muito menores. Portanto, se alguém morria porque não tinha acesso à UTI, não era uma situação tão dramática nem caracterizada como desigualdade porque este recurso ainda não existia. Era sonho alguém idealizar que esse recurso iria existir e que o sistema público já deveria estar oferecendo à população. Hoje seria muito mais dramático considerandose todo o avanço que ocorreu e isso tem tornado cada vez mais complexo o desafio de um sistema que possa contribuir com a justiça social no sentido de propiciar direitos iguais a $\operatorname{todos}^{(10)}$. O que se apresentou de início foi o desafio da igualdade muito mais do que o da eqüidade ${ }^{(10)}$, porque a igualdade é um desafio que antecede a equidade. Precisamos garantir o acesso a todos para, ao ter certeza de que nós estamos garantindo a todos condições iguais, poder garantir a alguns, condições diferenciadas do ponto de vista de prioridade.

$\mathrm{Na}$ Constituição Federal isso está claramente explicitado ao definir a saúde como direito de todos e dever do Estado, que era a bandeira de luta da Reforma Sanitária (que a Professora Anna Chiesa lembrou aqui que o departamento de Enfermagem em Saúde Coletiva nasce integrado nesse movimento). O Movimento da Reforma Sanitária foi um movimento político, articulado com o movimento pela redemocratização do país e que teve como objetivo garantir a todos o acesso aos serviços de saúde não só do ponto de vista assistencial, mas também do ponto de vista da promoção e da prevenção. E as leis, às quais já me referi: a Lei 8080 e Lei 8142 deram início ao processo de construção do SUS ${ }^{(3-4)}$.
Desse modo, do ponto de vista dos princípios, a universalidade significa que o SUS é para todos e a integralidade significa que é tudo. Assim, o nosso desafio é assegurar $t u$ do para todos. Esse é um grande desafio, porque se fosse tudo para alguns, ou alguma coisa para todos seria muito mais fácil. Mas tudo para todos é o grande desafio e, ao mesmo tempo, é a grande riqueza do SUS. Entendo que se pensarmos numa perspectiva de que o SUS seja para alguns, ou seja, parcial, que não garanta a integralidade, ele se desintegra no ar, porque essa que é a grande riqueza, que é o grande desafio que infelizmente não é bem entendido. Ou, pelo menos, bem defendido por todos. Pesquisas de opinião têm demonstrado que a parcela da população que não utiliza o SUS tem uma visão extremamente negativa do SUS. Talvez, porque vivenciar o SUS, defender e se comprometer com o SUS, é antes de tudo um ato de desprendimento, de solidariedade. Infelizmente a parcela da população que paga, muito caro, um plano ou seguro de saúde não consegue fazer esse exercício e de certo modo isto é até compreensível.

A equidade está entre os princípios do SUS, mas ainda é pouco desenvolvida e há pouco debate sobre isso. Além disto, temos outros princípios operacionais que são: a descentralização com a municipalização, a regionalização e a hierarquização de rede e a participação social. Vou fazer um comentário rápido sobre a descentralização ${ }^{(11)}$ e a regionalização porque num primeiro momento, talvez ao longo da década de 90, na implantação do SUS se priorizou muito a descentralização em detrimento da regionalização ${ }^{(11)}$. O que houve foi uma expectativa que se fosse concedido todo poder aos municípios, os problemas estariam resolvidos. Isso não é verdade. Nós temos que conceder todo poder sim ao município, mas esse município, ao mesmo tempo, deve estar integrando um sistema, integrando uma rede regional. Porque se não for desse modo, um conjunto aleatório de municípios autônomos não constitui automaticamente um sistema de saúde. Serão sistemas isolados e parciais. A verdade é que felizmente (alguns acham que infelizmente) não dá para nenhuma esfera de governo ter autonomia plena no SUS. Há uma interdependência permanente e completa. Permanente no tempo e completa porque ela é total, diferentemente de outras áreas. Por exemplo, na área de educação é impossível uma criança ir para o pré-primário pela manhã, à tarde estar na universidade e à noite estar fazendo doutorado. Mas, na saúde isso acontece. Uma criança pode utilizar serviços da Atenção Básica pela manhã, à tarde necessitar de um exame de alta complexidade e à noite pode estar internada em um hospital realizando uma neurocirurgia. A situação se torna ainda mais complexa porque não dá para se ter tudo em cada município, por uma questão de escala e por várias outras questões lógicas, inclusive a qualidade. Não é possível entender que os municípios possam ser totalmente autônomos. Portanto, temos que trabalhar essa questão de um modo diferente. Às vezes se fala muito em dialética, mas se pensa muito pouco de forma dialética, que é a unidade e, ao mesmo tempo, a unidade constituindo um conjunto. Esta é uma perspectiva às vezes 
bastante complicada, mas é sem dúvida importante. O que importa é que no nível operacional, para se ter igualdade e também eqüidade, é necessário que a descentralização propicie que o município, ao mesmo tempo integre uma rede e possa prover à po-pulação que vive naquele local a oferta equivalente à dimensão da sua necessidade. Ou seja, quanto mais se descentraliza, mais se foge da cilada da média. Porque a média é aquela história que diz que a taxa de mortalidade infantil no Estado de São Paulo é 13,28 óbitos por mil nascidos vivos, mas tem municípios com taxa de 19 óbitos por mil nascidos vivos, municípios com taxa de nove, e municípios com 12 óbitos por mil nascidos vivos. Ou seja, a média não representa cada realidade nem nenhuma realidade específica. Então, quanto mais se foge da média mais se vai dar o tratamento justo à correspondente necessidade que é, em última análise, o que estamos definindo como eqüidade.

Agora, vou fazer alguns comentários sobre a participação da população, que alguns preferem chamar de controle social. Eu prefiro chamar de participação social porque entendo que o controle é uma parte disso e que temos ainda muito a andar e a evoluir, porque a saúde não é um paraíso descolado do resto da nossa sociedade mas sim parte dela. Então, temos mais participação ou menos participação, mais manipulação ou menos manipulação na dependência do próprio exercício de cidadania que é resultado do nível de consciência política de uma determinada população.

Ainda se tratando de igualdade, do ponto de vista de acesso, há que se considerar o quanto se tem conseguido evoluir com o Sistema Único de Saúde, em que pesem todas as dificuldades e as críticas que ele recebe, algumas justas, outras absolutamente injustas. Muitos avanços se têm conseguido, por exemplo, com relação à Atenção Básica, tanto na área da prevenção como no crescimento da oferta das ações básicas de saúde. O SUS tem um problema que eu digo que é um problema da herança. Para muita gente que acha que o SUS é a continuidade do INAMPS e assim só vê o SUS quando aparecem na imprensa os pacientes nas macas no corredor do pronto socorro, todos os outros avanços, tais como os transplantes e o programa da AIDS não são vistos como ações do SUS. Porém, na hora que tem uma maca no corredor do pronto socorro, aí é o SUS que é ineficiente e que o problema não é de falta de recursos, que o problema é de falta de capacidade gerencial, do modelo que é ruim, que é um sonho querer dar saúde para todos e que isto é impossível.

Citando aqui dois exemplos específicos no Estado de São Paulo, temos o Programa Dose Certa, em que o Governo do Estado produz a maioria dos medicamentos, mas também há aquisição e distribuição de medicamentos para todos os municípios. Apenas alguns dos municípios com mais de 200 mil habitantes escolheram receber os recursos financeiros estaduais e federais para aquisição de medicamentos, a maioria recebe no município uma farmácia básica com 41 medicamentos, que está sendo ampliada para 67 medicamentos, inclusive contraceptivos.
O programa de assistência aos diabéticos é uma iniciativa que é bastante inovadora, principalmente, quando se integram as dificuldades de todo o processo logístico, que inclui o governo federal, o estadual e 645 municípios para o fornecimento dos insumos para o paciente portador de diabetes. Esse programa propicia que o usuário possa fazer o controle da glicemia e a auto-aplicação da insulina, além do fornecimento da própria insulina, seringas, agulhas, enfim tudo o que é necessário. Isso, o SUS-SP tem hoje espalhado por todo o Estado, com mais de 145 mil pacientes cadastrados. Importante destacar que esse programa foi totalmente negociado na Comissão Intergestora Bipartite (CIB). Esse processo de negociação é bastante complexo, mas muito significativo para viabilizar os acordos para que a política venha a acontecer na prática.

Falando mais genericamente do SUS, temos o programa do controle da aids que é internacionalmente reconhecido. Esse caso e o anterior são exemplos do exercício progressivo de busca da eqüidade no sentido de identificar uma população específica, com uma necessidade específica, com uma complexidade específica. Nesse caso, eu estou falando do ponto de vista de patologia, mas isso se dá também em termos de condição de vida, da região de moradia e uma série de outras variáveis.

É inegável o avanço que temos no país, também do sistema de transplantes e nisso São Paulo desempenha um papel extremamente significativo. Na verdade, em alguns aspectos o SUS - São Paulo é nacional como é, na verdade, a sua população. Do ponto de vista da saúde, se vê facilmente na cidade que o Brasil inteiro está aqui. Não só quanto aos pacientes, mas também quanto aos profissionais, porque temos aqui profissionais de diversas origens, de diversas regiões do Brasil e de outros países. Retomando o exemplo dos transplantes, tem havido um crescimento extremamente significativo a partir da organização do Sistema Nacional de Transplante. Em relação a 1997, que foi quando se iniciou a regulamentação, aqui no Estado de São Paulo, o transplante de rim cresceu $134 \%$ e de fígado $162 \%$.



Fonte: Sistema Estadual de Transplantes - SES-SP - 2007

Figura 1 - Dados sobre mortalidade infantil - São Paulo - 2007 
Na Figura 1 pode-se verificar, rapidamente um exemplo dos avanços que se tem conseguido. No caso, trata-se da redução da mortalidade infantil; tínhamos uma taxa de praticamente 25/1000 em 1995 e agora temos pouco mais de 13 por mil nascidos vivos. Mas tem-se que destacar que persiste uma distribuição absolutamente desigual dentro do Estado, porque temos municípios com taxa de mortalidade infantil em torno de 20 óbitos por mil nascidos vivos e municípios com taxa de mortalidade infantil de um dígito. São 250 cidades com taxas de mortalidade infantil de um digito, o que é um padrão excepcional. Então, temos uma situação desigual que exige uma política de tratar desigualmente os desiguais. Ou seja, fazer uma discriminação positiva para alcançar a eqüidade: dar mais às populações que estão necessitando de mais para propiciar maior avanço na redução da mortalidade infantil ${ }^{(12)}$.

Alguns dados reforçam a idéia do quanto avançamos no que toca à universalidade. Um estudo feito pela FIOCRUZ em parceria com a OMS refere que $97 \%$ das pessoas pesquisadas afirmaram ter recebido a assistência que precisaram ou no setor público ou no setor privado. Destas, $87 \%$ obtiveram todos os medicamentos prescritos, ou seja, compraram ou receberam do sistema público. Dos que necessitaram de internação, $71 \%$ foram atendidos pelo SUS e a maior parte teve acesso a essa internação de imediato ${ }^{(13)}$.

A avaliação positiva da assistência ambulatorial do SUS é de $70 \%$, ou seja, nota $7^{(14)}$. Eu acho que nota sete é uma nota muito boa. Na internação é de $68 \%$, que também é uma nota muito boa. Mas essa é a avaliação de pessoas que utilizaram o sistema porque quem não utiliza, normalmente, tem uma avaliação muito mais negativa. Essa avaliação negativa é muito mais da imagem do que da vivência, porque essas pessoas não vivenciaram o SUS. Isso mostra que temos que reconhecer que o principal problema do SUS ainda é o acesso, porque quem tem acesso avalia de forma muito positiva.

A despeito disso, o SUS ainda tem muitos problemas com o acesso, muitas vezes representado pelas filas. Esse problema é também desigualmente distribuído no território, tanto no território nacional quanto no território estadual e até mesmo no municipal. Temos também problemas com a qualidade. Temos um grave problema que é relacionado ao porte dos hospitais. Eu explico com um exemplo: mais da metade dos hospitais do Estado de São Paulo (e no Brasil esse número é um pouco maior) têm menos de 50 leitos. São pequenas unidades hospitalares que não têm condições de garantir e dar sustentação a uma assistência de qualidade, pois existem algumas condições mínimas que estes hospitais não atendem. Desse modo, um lugar que não dispõe de recursos básicos, como: gerador, aparelhos de suporte de vida, laboratório que funcione 24 horas, médico nas 24 horas, e enfermeiro em nenhum horário de funcionamento não pode ser chamado de hospital.
Para enfrentar estas questões nós teríamos que resolver vários problemas e um deles, na verdade, é a conjugação de dois quais sejam: gastos crescentes e recursos limitados. Os gastos serão sempre crescentes e os recursos serão sempre limitados. É importante dizer que quem está com a expectativa de que em alguns anos vai poder descansar, porque os gastos vão parar de crescer e os recursos vão sobrar, desista porque não há a menor possibilidade disto acontecer.

Crescem os gastos porque - ainda bem - estamos ampliando o acesso. Crescem os gastos porque a população está envelhecendo - ainda bem - o que significa que as pessoas estão vivendo mais. Crescem os gastos porque - ainda bem - a medicina se desenvolve, cada dia surgem novos recursos, embora alguns não justifiquem os custos, mas sempre tendo mais recursos diagnósticos e assistenciais. E os recursos vão ser sempre limitados, principalmente em um país pobre como o nosso. Penso que o Brasil deveria gastar bem mais ainda com saúde, mas nunca gastaria tanto que nos assegurasse tranqüilidade. Além do mais, se tomarmos os recursos atualmente disponíveis e multiplicássemos por 10 , nos primeiros seis meses sobraria dinheiro; depois, tornarse-iam mais ou menos justo e, no máximo em um ano, já estaria faltando dinheiro. Porque as necessidades são realmente infinitas.

\section{CONCLUSÕES}

Concluindo, teço um comentário em relação à afirmativa que se faz, aqui e ali, de que o principal problema do SUS é de gerenciamento ${ }^{(14)}$ e não de financiamento. É inegável que temos um problema de gerenciamento, pois como se conseguiria implantar um sistema descentralizado com mais de 5.500 municípios em pouco tempo sem ter um período de carência, sem dispor de recursos humanos qualificados? Mesmo reconhecendo que tem havido um esforço grande para a qualificação de recursos humanos para a gestão do SUS, esse esforço precisaria ser ainda muito maior, principalmente, nos pequenos municípios. Mas, se tomarmos os dados de 2004, de que o gasto do sistema público, somando os gastos federais, estaduais e municipais, chegou a mais ou menos R \$ 360 per capita/ano, para um atendimento integral e universal, vemos o quanto é insuficiente. Como referência, podemos tomar os gastos dos planos e seguros de saúde, que no mesmo período foram em média de R \$ 864 per capita/ mês. Quando se sabe que nenhum plano ou seguro de saúde garante a integralidade da atenção à saúde. Assim, boa parte da população com necessidade de tratamento para câncer, transplante, doença mental e uma série de outras situações, como o uso de endopróteses, recorre ao sistema público de saúde. Diante desses dados, eu ainda acho que nós estamos operando alguns pequenos milagres, cotidianamente, de conseguir com esse pouco financiamento, os resultados que o SUS vem conseguindo. 
Outro comentário, ainda em relação ao financiamento, é que estamos longe de ter eqüidade, porque ainda há uma distribuição extremamente desigual dos recursos. Isto tem a ver não só com os recursos federais, mas inclusive com os recursos estaduais e os municipais ${ }^{(10-14)}$. Porque, normalmente, os municípios mais pobres, com população mais pobre e com mais necessidades, têm capacidade menor de buscar, de obter recursos e, conseqüentemente, capacidade gerencial menor

\section{REFERÊNCIAS}

1. Houaiss A, Villar MS. Dicionário Houaiss da língua portuguesa. $4^{\mathrm{a}}$ ed. Rio de Janeiro: Objetiva; 2001. p. 1183, p. 1569.

2. Brasil. Ministério da Saúde. Reduzindo as desigualdades e ampliando o acesso à assistência à saúde no Brasil 1998 - 2002. Brasília; 2002.

3. Brasil. Lei n. 8.080, 19 de setembro de 1990. Dispõe sobre as Condições para Promoção e Recuperação da Saúde, a Organização e o Funcionamento dos Serviços Correspondentes e dá outras providências. Diário Oficial da União, Brasília, 20 set. 1990. Seção 1, p. 018055.

4. Brasil. Lei n. 8.142, 28 de dezembro de 1990. Dispõe sobre a participação da comunidade na gestão do Sistema Único de Saúde (SUS) e sobre as transferências intergovernamentais de recursos financeiros na área e saúde, e dá outras providências. Diário Oficial da União, Brasília, 31 dez. 1990. Seção 1, p. 025694.

5. Brasil. Ministério da Saúde. Saúde no Brasil: relatório. Brasília; 1995.

6. Brasil. Conselho Nacional de Secretários de Saúde. Legislação do SUS. Brasília; 2003.

7. Brasil. Ministério da Saúde. NOB - 96 - Norma Operacional Básica do Sistema Único de Saúde - SUS [legislação na Internet]. Brasília; 1996. [citado 2007 jul. 15]. Disponível em: http:// siops.datasus.gov.br/Documentacao/NOB\%2096.pdf

8. Levicovitz E. Transição x consolidação: o dilema estratégico da construção do SUS - um estudo sobre as reformas da política nacional de saúde [tese]. Rio de Janeiro: Instituto de Medicina Social, Universidade Estadual do Rio de Janeiro; 1997. para realizar os gastos para sua população ${ }^{(15)}$. Esta situação conspira contra o princípio de eqüidade. O que ocorre é uma situação que é exatamente o inverso do que se pretenderia do ponto de vista do atendimento do princípio da eqüidade ${ }^{(16)}$.

Em linhas gerais é isso que eu queria colocar, agradecer mais uma vez o convite e me colocar à disposição para o debate.

9. Souza RR. O sistema público de saúde brasileiro. In: Negri B, Viana ALD, organizadores. O Sistema Único de Saúde em dez anos de desafios. São Paulo: Sobravime; 2002. p. 240-67.

10. Finkelman J. Análise de equidade: saúde. Brasília: OPAS; 2000.

11. Brasil. Ministério da Saúde. Portaria GM/MS n. 95, de 26 de janeiro de 2001. Aprova, na forma do Anexo desta Portaria a Norma Operacional de Assistência à Saúde - NOAS-SUS 01/ 2001, que amplia a regionalização da assistência [legislação na Internet]. Brasília; 2001. [citado 2007 jul. 15]. Disponível em: http://ww2.prefeitura.sp.gov.br//arquivos/secretarias/saude/ legislacao/0165/PortariaGM_2001_0095.pdf

12. Fundação SEAD. São Paulo demográfico: resenha de estatísticas vitais do estado de São Paulo. São Paulo; 2007.

13. Fundação Oswaldo Cruz (FIOCRUZ). O Brasil em números: pesquisa mundial de saúde - 2003. RADIS Comum Saúde. 2004;(24):14-23.

14. Brasil. Conselho Nacional de Secretários de Saúde. Para entender a gestão do SUS. Brasília; 2003.

15. Souza RR. Construindo o SUS: a lógica do financiamento e o processo de divisão de responsabilidades entre as esferas de governo. In: Pierantoni CR, Vianna CMM, organizadores. Gestão de sistemas de saúde [CD-ROM]. Rio de Janeiro: SegrecaR; 2003.

16. Souza RR. Redução das desigualdades regionais na alocação dos recursos federais para a saúde. Cienc Saúde Coletiva. 2003; 8(2):449-60. 